\title{
Duodenal mucosa in children with coeliac disease in catamnesis and varying compliance with the gluten-free diet
}

\author{
Uspenskaya ID, Shirokova NY \\ Federal State Establishment "Nizhniy Novgorod Research Institute of Pediatric Gastroenterology”, the Small Intestine Pathology \\ Department, Laboratory of Pathomorphology, Nizhniy Novgorod, Russia. iusp@mail.ru
}

\begin{abstract}
Objectives: the aim of the study was to identify the characteristic morphometric data changes in the small intestine mucosa in response to varied compliance with gluten-free diet in children with coeliac disease. Methods: 71 children (47 girls and 24 boys) aged 2.5 to 16.5 (median age=10.6) with coeliac disease diagnosed according to the previously revised ESPGHAN criteria were included in the study. The patients were divided into three groups: 1 - on strict GFD, 2 - on semistrict GFD, 3 - not on GFD. Quantitative morphometric data on biopsies of duodenal mucosa in each group were compared with each other.

Results: As compared with group 1, patients from group 2 had a lower villous height (Vh)/crypt depth (Cd) ratio, but a higher $\mathrm{Cd}$, total cell density of lamina propria, plasma cells density in the villi and fibroblasts density in the space between the crypts. In patients from group 3, as compared with group 1, we found a significant reduction in $\mathrm{Vh}$ and $\mathrm{Vh} / \mathrm{Cd}$ ratio, and a significant decrease in the number of goblet cells. At the same time they yielded an increase in Cd, number of intraepithelial lymphocytes (IEL), total cell density and plasma cells density throughout the lamina propria depth, number of macrophages and neutrophils in the villous lamina propria, and number of fibroblasts in the space between crypts. The differences were statistically significant.

Conclusion: Quantitative morphometric parameters of small intestine mucosa allow revealing statistically significant differences between the groups of children with coeliac disease in response to varied compliance with GFD. This enables us to assess the dynamics of the pathological process and enhance our understanding of its nature, which is very important for improving the therapy and prognosis (Ref. 40). Text in PDF www.elis.sk.

Key words: coeliac disease, children, gluten-free diet, compliance with diet, small intestine morphometry.
\end{abstract}

Coeliac disease (CD), or gluten-sensitive entherophathy, is an important medical and social problem of the world public health. Population-based studies indicate that this pathology can be found in $1 \%$ of the population (1-3), and increases to 5-15\% among close relatives of patients, as well as among patients with autoimmune diseases $(4,5)$. The triggering factor in the development of coeliac disease is gluten - a protein, which is found in grains (wheat, rye, barley). This disease has a complicated and dynamic character of pathophysiological mechanisms, which are manifested by clinical polymorphism, gastrointestinal symptoms of varying severity (diarrhea, polyfecalia, recurring abdominal pain, abdominal swelling, vomiting), and nongastrointestinal symptoms (anemia, stunting, weight loss, delayed sexual development, osteoporosis, osteomalacia, reduced serum albumin). This makes coeliac disease difficult to diagnose and monitor $(6,7)$.

Currently CD is seen as an immune-mediated systemic disorder caused by gluten and related prolamines in genetically sus-

Federal State Establishment "Nizhniy Novgorod Research Institute of Pediatric Gastroenterology”, the Small Intestine Pathology Department, Laboratory of Pathomorphology, Nizhniy Novgorod, Russia

Address for correspondence: I.D. Uspenskaya, MD, the Head of the Small Intestine Pathology Department, Federal State Establishment "Nizhniy Novgorod Research Institute of Pediatric Gastroenterology", Semashko Street, 22, 603950 Nizhniy Novgorod, Russia.

Phone: +79101408315 ceptible individuals. It is characterized by the presence of a variable combination of gluten-dependent clinical manifestations, CD-specific antibodies, HLA-DQ2 or HLA-DQ8 haplotypes, and enteropathy (8).

Gluten comes into the body with food, and the main target of its toxic influence is small intestine. In the small intestine mucosa, an immune-inflammatory process develops. This process begins with the activation of T-lymphocytes and results in cytokines production and release of matrix metalloproteinases, which eventually cause epithelial damage and villi destruction $(9,10)$. Such mucosa changes lead to intestinal malabsorption. The current gold standard of CD diagnosis verification remains to rely on morphological study of mucosa biopsy material taken from distal duodenum or initial jejunum departments. The characteristic pathological changes in mucosa include signs of hyperregenerative atrophy with varying degrees of villous atrophy, and crypts deepening (hyperplasia), as well as with infiltration with immune cells, namely an increase in intraepithelial lymphocytes (IEL) on the villi, and lymphoplasmacytic infiltration of the lamina propria $(11,12)$.

The dynamics and staging of the changes in the morphological picture of small intestine mucosa in coeliac disease are shown in M.N. March's classification $(13,14)$, in the modified classification of March-Oberhuber (15) and the classification of CorazzaVillanacci (16). They all have made a significant contribution to the improvement in diagnostic procedures of this pathology. 
Nevertheless, we must admit that there are problems in interpreting histopathological criteria, which may lead to disagreements among pathologists and clinicians, and sometimes give rise to misdiagnosis, incorrect assessment of the pathological process severity, and wrong prognosis. This, in turn, reduces the positive effects of the management of patients with coeliac disease. A more precise and objective way to document the changes in biopsy of the small intestine of each individual patient is the morphometric study involving an accurate measurement of the quantitative parameters of mucosa $(17,18)$.

The basic method of treatment for coeliac disease is a lifelong gluten-free diet (19-21). Recent studies have shown that due to various social and psychological reasons, not all patients, when diagnosed with coeliac disease, adhere to strict gluten-free diet (GFD). According to a number of authors, about 27-75\% of children and adult patients follow the gluten free diet strictly (22-25). Quitting the GFD may lead to reappearance of symptoms as well as to an increase in risk of long-term complications, including malignant diseases $(6,26)$. Clinical manifestation and complications of $\mathrm{CD}$ are thought to be pathogenetically related to the ongoing duodenal inflammation /injury (27). Therefore, it is very important to have the most detailed information about the pathological process development in the small intestine mucosa to monitor the compliance with the diet in patients with coeliac disease. This information can be obtained through morphometric study of biopsies from small intestine. There have been several studies of some morphometric parameters in patients on the gluten-free diet (28). However, numerous morphometric parameters of small intestine mucosa and their relation to the varied degree of the patients' compliance with GFD require a more thorough investigation. In our opinion, such studies are likely to expand our understanding of the mechanisms involved in the changes in intestinal mucosa structure in coeliac disease and enhance our understanding of the causes underlying the varied ways of the disease development. They will also contribute to a more precise prognosis, which will enable us to find an optimal treatment policy for each individual patient and improve the quality of clinical observation.

The aim of our study was to identify the structural features of duodenal mucosa by analyzing them morphometrically in relation to gluten-free diet compliance of children with coeliac disease in catamnesis.

\section{Material and methods}

We examined 71 children (47 girls and 24 boys) diagnosed with coeliac 1.5-14 years ago. The median age of the patients was 10.6 years (ranging from 2.5 to 16.5 ). CD was diagnosed by the revised criteria of European Society for Pediatric Gastroenterology, Hepatology and Nutrition (29). The patients' compliance with the gluten-free diet was revealed through special interviews.

By their compliance with the gluten-free diet, the patients were subdivided into three groups: the first group consisted of those with strict compliance with GFD ( 16 children, making up $22.5 \%$ ), the second one consisted of patients on a semistrict diet (35 children, $49.3 \%$ ), and the third group consisted of patients who did not adhere to GFD (20 children, $28.2 \%$ ). All the groups of patients were comparable by sex and age (the median age in groups 1, 2 and 3 was $8.4,9.8$ and 12.8 years, respectively; $\mathrm{p}=0.14$ ).

All children had gastrointestinal endoscopy with the distal duodenum mucosa biopsy. The samples were preserved in 10 $\%$ neutral formalin, embedded in paraffin, cut, and stained with hematoxylin and eosin for subsequent light microscopy and morphometry. The samples were examined by 2 pathologists with long-standing experience in morphometric analysis who were blinded to subject assignment. The well-oriented biopsy samples were analyzed by villous height (Vh), crypt depth $(\mathrm{Cd})$, number of intraepithelial lymphocytes (per 100 enterocytes), goblet cells (per 100 enterocytes), as well as by total cell density and number of individual cell forms in 1 square mm of villous lamina propria and space between the crypts. These were studied with a Nikon Eclipse E400 microscope.

The study was conducted in compliance with the Protocol, approved by the Local Committee on Biomedical Ethics of the Federal State Establishment "Nizhniy Novgorod Research Institute of Pediatric Gastroenterology", in accordance with the Helsinki Declaration, and a signed informed consent was obtained from each patient and their parents.

The data were analyzed using the statistical environment $R$, version 2.14 (URL: http://www.r-project.org/). Normal (or Gaussian) distribution was estimated through the test of normality (the Shapiro-Wilks W-test and Kolmogorov-Smirnov test). To test for the equality of dispersions we used the Leuven criterion. We

Tab. 1. Villi height, crypt depth, villi height/crypt depth ratio, intraepithelial lymphocytes, goblet cells in duodenum mucosa in the studied groups of children with coeliac disease (Me; Q1-Q3).

\begin{tabular}{|c|c|c|c|c|}
\hline \multirow[b]{2}{*}{ Parameter } & \multicolumn{3}{|c|}{ Group } & \multirow{2}{*}{$\begin{array}{l}\text { P value } \\
\text { (U test) }\end{array}$} \\
\hline & $\begin{array}{c}\text { Strict } \\
\text { GFD (1) }\end{array}$ & $\begin{array}{l}\text { Semistrict } \\
\text { GFD (2) }\end{array}$ & $\begin{array}{c}\text { Not on } \\
\text { GFD (3) }\end{array}$ & \\
\hline $\mathrm{Vh}, \mu \mathrm{m}$ & 364 & 198 & 77 & $1-2<0.00$ \\
\hline
\end{tabular}

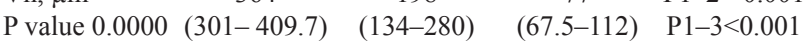

$(\mathrm{K}-\mathrm{W}) \quad \mathrm{P} 2-3<0.001$

$\begin{array}{lllll}\mathrm{Cd}, \mu \mathrm{m} & 224 & 308 & 336 & \mathrm{P} 1-2=0.001\end{array}$

$\begin{array}{lllll}P \text { value } 0.0007 & (196-283.5) & (259-329) & (266-350) & \mathrm{P} 1-3<0.001\end{array}$

$(\mathrm{K}-\mathrm{W}) \quad$ P2-3 NS

$\begin{array}{lllll}\mathrm{Vh} / \mathrm{Cd} & 1.69 & 0.62 & 0.26 & \mathrm{P} 1-2<0.001\end{array}$

$\begin{array}{lllll}\mathrm{P} \text { value } 0.0000 & (1.02-2.07) & (0.38-1.07) & (0.19-0.31) & \mathrm{P} 1-3<0.001\end{array}$

$(\mathrm{K}-\mathrm{W}) \quad \mathrm{P} 2-3<0.001$

$\begin{array}{lcccc}\text { IEL/100 } & 26 & 30 & 32 & \mathrm{P} 1-2 \mathrm{NS} \\ \text { villi enterocytes } & (23.3-29) & (23-36.5) & (29-46) & \mathrm{P} 1-3=0.006 \\ \text { P value } 0.018 & & & & \text { P2-3 NS }\end{array}$

$(\mathrm{K}-\mathrm{W})$

\begin{tabular}{lcccc}
\hline Goblet & 9 & 7 & 5 & P1-2 NS \\
cells/100 villi & $(5.75-10)$ & $(5-9)$ & $(4.25-8)$ & P1-3=0.01 \\
enterocytes & & & & P2-3 NS
\end{tabular}

enterocytes

$P$ value $=0.03$

$(\mathrm{K}-\mathrm{W})$

$\mathrm{Vh}$ - villi height, $\mathrm{Cd}$ - crypt depth, $\mathrm{Vh} / \mathrm{Cd}$ - villi height/crypt depth ratio, IEL - intraepithelial lymphocytes, $\mathrm{K}-\mathrm{W}$ - Kruskal-Wallis H-test; U-Mann-Whitney U-test, $\mathrm{P}$ - level of significance), NS - non-significant, P1-2 - statistically significant differences between Groups 1 and 2: P1-3 - statistically significant differences between Groups 1 and 3; P2-3 - statistically significant differences between Groups 2 and 3. 
used the nonparametric alternative for t-test to evaluate the differences in means between the groups because the variables were not normally distributed within each group and the variation of scores in all groups was reliably different, as well as nonparametric indexes (median, maximum and minimum). In the course of comparison of the three independent quantitative samples, the overall inter-group differences of quantitative indicators were evaluated through Kruskal-Wallis H-test. The differences were considered statistically significant at $\mathrm{p}<0.05$. For the pairwise comparison between the groups, we used the Mann-Whitney Utest with Bonferroni correction for multiple comparisons, a new critical significance making 0.017 . The results were presented as median $(\mathrm{Me})$ and interquartile ranges (Q1-Q3) between the lower (25\%) and upper (75\%) quartiles.

\section{Results}

The summarized results of the morphometric data on duodenal mucosa in children with coeliac disease in the two groups under comparison are shown in Tables 1 and 2 (only the parameters with statistically significant differences are given). Significant differences between the three groups have been found through the Kruskal-Wallis H-test for median values for villous height (H-test 39.3; $\mathrm{p}=0.0000)$, crypts depth (H-test 14.6; $\mathrm{p}=0.0007)$, the ratio of the villous height to the crypts depth $(\mathrm{Vh} / \mathrm{Cd})(\mathrm{H}$-test $31.6 ; \mathrm{p}=0.0000)$, the number of intraepithelial lymphocytes (H-test $8.0 ; \mathrm{p}=0.018)$ and the number of goblet cells (H-test 7.0; $\mathrm{p}=0.03$ ) in the villous epithelium.

When comparing the group of children with strict compliance with GFD and the group of patients on semistrict GFD, we found that in the latter group the villous height value was lower $(\mathrm{p}<0.001)$, the crypts depth value was higher $(\mathrm{p}=0.001)$ and the $\mathrm{Vh} /$ $\mathrm{Cd}$ ratio was smaller $(\mathrm{p}<0.001)$. However, between these groups of patients, we have not found any significant differences in the number of intraepithelial lymphocytes and goblet cells (Tab. 1).

When comparing the group of coeliac patients with strict GFD compliance and those not on GFD, in the latter group, we found even a more significantly reduced value of the villous height $(p<0.001)$, increased value of crypts depth $(p<0.001)$, decreased $\mathrm{Vh} / \mathrm{Cd}$ ratio, as well as an increase in the number of intraepithelial lymphocytes $(p=0.006)$ and a decrease in the number of goblet cells $(\mathrm{p}=0.01)$.

In patients not on GFD, the villous height value $(\mathrm{p}<0.001)$ and $\mathrm{Vh} / \mathrm{Cd}$ ratio $(\mathrm{p}<0.001)$ were smaller than those in the group of patients on semistrict GFD.

While assessing the morphometric parameters of duodenum mucosa lamina propria (Tab. 2) through the Kruskal-Wallis H-test, we found significant differences in the median values of intravillus lamina propria cell density (H-test 21.5; $\mathrm{p}=0.0000$ ), density of plasma cells within villous stroma (H-test 12.6; $\mathrm{P}=0.0018$ ), macrophage density (H-test $12.9 ; \mathrm{p}=0.0016)$, neutrophil density (H-test 7.7; $\mathrm{p}=0.021)$, total cell density in the space between the crypts (H-test 16.8; $\mathrm{p}=0.0002)$, plasma cells density (H-test 10.0; $\mathrm{p}=0.0067$ ) and fibroblast density (H-test 10.9; $\mathrm{p}=0.004$ ).

In the group of children on semistrict GFD, villous lamina propria total cell density $(\mathrm{p}<0.001)$ and plasma cells density $(\mathrm{p}=0.005)$, as well as lamina propria total cell density in the space between the crypts $(p=0.003)$ and fibroblastic density in the space between the crypts $(p=0.004)$ were significantly higher than in the group of children with CD on strict GFD.

Tab. 2. Morphometric parameters of duodenum mucosa lamina propria in the studied groups of children with coeliac disease (Me; Q1-Q3).

\begin{tabular}{|c|c|c|c|c|}
\hline \multirow{2}{*}{ Indicators } & \multicolumn{3}{|c|}{ Group } & \multirow{2}{*}{$\mathrm{P}$ value ( $\mathrm{U}$ test) } \\
\hline & Strict GFD (1) & Semistrict GFD (2) & Not on GFD (3) & \\
\hline Cell density in villi & 9238 & 10181 & 10793.5 & $\mathrm{P} 1-2<0.001$ \\
\hline \multirow{2}{*}{$\begin{array}{l}\text { P value } 0.0000 \\
(\mathrm{~K}-\mathrm{W}\end{array}$} & $(8484-9427)$ & $(9379.5-11453.5)$ & $(10369-11571.5)$ & $\mathrm{P} 1-3<0.001$ \\
\hline & & & & P2-3 NS \\
\hline Plasmatic cells density in villi & 2121 & 2546 & 2875 & $\mathrm{P} 1-2=0.005$ \\
\hline \multirow{2}{*}{$\begin{array}{l}\text { P value } 0.0018 \\
(\mathrm{~K}-\mathrm{W})\end{array}$} & $(1885-2521.8)$ & $(2168-3064)$ & $(2592.8-3181.5)$ & $\mathrm{P} 1-3<0.001$ \\
\hline & & & & P2-3 NS \\
\hline Macrophage density in villi & 377 & 472 & 472 & P1-2 NS \\
\hline \multirow{2}{*}{$\begin{array}{l}\mathrm{P} \text { value } 0.0016 \\
(\mathrm{~K}-\mathrm{W})\end{array}$} & $(283-377)$ & $(283-472)$ & $(472-542.5)$ & $\mathrm{P} 1-3<0.001$ \\
\hline & & & & P2-3 NS \\
\hline \multirow{3}{*}{$\begin{array}{l}\text { Neutrophilic density in villi } \\
\text { P value } 0.021 \\
(\mathrm{~K}-\mathrm{W})\end{array}$} & 94 & 189 & 189 & P1-2 NS \\
\hline & $(94-189)$ & $(94-236)$ & $(189-283)$ & $P 1-3=0.007$ \\
\hline & & & & P2-3 NS \\
\hline \multirow{3}{*}{$\begin{array}{l}\text { Cell density in the space between crypts } \\
\mathrm{P} \text { value } 0.0002 \\
(\mathrm{Kr}-\mathrm{W})\end{array}$} & 9898 & 11123 & 11359 & $\mathrm{P} 1-2=0.003$ \\
\hline & $(9379.5-10322.3)$ & $(10181-$ & $(10793.5-12136.5)$ & $\mathrm{P} 1-3<0.001$ \\
\hline & & 11689) & & P2-3 NS \\
\hline \multirow{3}{*}{$\begin{array}{l}\text { Plasmatic cell density in the space between crypts } \\
\text { P value } 0.0067 \\
(\mathrm{~K}-\mathrm{W})\end{array}$} & 2121 & 2357 & 2686.5 & P1-2 NS \\
\hline & $(1767.5-2521.8)$ & $(2026.5-2734)$ & $(2545-3016)$ & $P 1-3=0.004$ \\
\hline & & & & $\mathrm{P} 2-3=0.015$ \\
\hline \multirow{3}{*}{$\begin{array}{l}\text { Fibroblast density in the space between crypts } \\
\text { P value } 0.004 \\
(\mathrm{~K}-\mathrm{W})\end{array}$} & 2074 & 2262 & 2262 & $\mathrm{P} 1-2=0.004$ \\
\hline & $(1980-2262)$ & $(2168-2498)$ & $(2262-2451)$ & $\mathrm{P} 1-3=0.002$ \\
\hline & & & & P2-3 NS \\
\hline
\end{tabular}

Density of all cell forms is expressed as the number of total cells or the number of individual cells forms per $1 \mathrm{~mm} 2$ of lamina propria in the villi and the space between the crypts. $\mathrm{K}-\mathrm{W}$ - Kruskal-Wallis H-test; U - Mann-Whitney U-test, P - level of significance), NS - non-significant, P1-2 - statistically significant differences between Groups 1 and 2: P1-3 - statistically significant differences between Groups 1 and 3; P2-3 - statistically significant differences between Groups 2 and 3. 
When comparing the group on strict GFD and that not on GFD, we found that in the absence of GFD, the total cell density $(\mathrm{p}<0.001 ; \mathrm{p}=0.007)$ and plasma cells density $(\mathrm{p}<0.001 ; \mathrm{p}=0.004)$ were significantly higher throughout the depth of the lamina propria (in the villi and intercrypt space). In addition, the number of macrophages $(\mathrm{p}<0.001)$ and neutrophils $(\mathrm{p}=0.007)$ increased in lamina propria of willi, as well as that of fibroblasts $(\mathrm{p}=0.002)$ in the intercrypt space.

The children in the group not on GFD had a higher plasma cells density in the space between the lamina propria crypts $(\mathrm{p}=0.015)$ than those on semistrict GFD.

\section{Discussion}

Coeliac disease is very common, its necessary trigger being gluten. It is known that the life-long gluten-free diet is the cornerstone in the treatment of coeliac disease and a necessary condition to prevent the recurrence of intestinal lesions and severe complications. However, in many countries it is difficult for patients with coeliac disease to adhere to GFD. Along with this problem, it is not easy to monitor the degree of compliance with the diet in patients with coeliac disease in catamnesis. Monitoring the histological response is the most valid method to evaluate the compliance with GFD (30). However, the impact of diet on the state of small intestine mucosa is insufficiently studied in catamnesis of children with coeliac disease. When reflecting the pathologic process, the most objective characteristics of mucosa histostructure can be obtained through morphometric study $(17,18)$.

The investigation of duodenal mucosa in 71 children with coeliac disease in our clinic has shown that the differences in morphometric parameters between the three groups of patients, i.e. those on strict GFD, those on semistrict GFD and those not on GFD were statistically significant.

This work has shown that the abnormal morphology of small intestine is revealed not only in the absence of GFD, but also in case of partial adherence. Intermittent use of gluten by the children on semistrict GFD, as compared with those on strict GFD manifested in form of changes in parameters as follows: villous height, crypt depth, $\mathrm{Vh} / \mathrm{Cd}$ ratio, lamina propria cell density at all depths, plasma cells density of lamina propria in the villi and fibroblastic density in the space between the crypts, while there were no significant changes in the number of goblet cells and intraepithelial lymphocytes. The data on intraepithelial lymphocytes differ from those obtained by other authors (31), who found an increase in intraepithelial lymphocytes in patients with rare consumption of small amounts of gluten. The number of IEL is considered to be one of the earliest and most sensitive signs of coeliac enteropathy $(32,33)$. However, we share the view that this indicator, typical for active coeliac disease, does not necessarily apply to patients who have received long-term treatment (34).

The most severe small intestine mucosa damage in form of atrophic and immuno-inflammatory changes aggravation was observed in patients not on GFD as compared with the group on strict GFD. This manifested in a sharp decrease in the villous height, significant deepening of the crypts, decrease in $\mathrm{Vh} / \mathrm{Cd}$ ratio, increase in the number of IEL, decrease in the number of goblet cells, growth of total cell density along the entire depth of lamina propria, growth of plasma cells density, as well as increase in the number of macrophages and neutrophils in lamina propria, of the villi, and increase in the number of fibroblasts in the space between the crypts. These results suggest that regular continuous consumption of gluten-containing products in patients with coeliac disease causes persistent inflammation in small intestine mucosa (35). The increase in the number of lymphocytes in the epithelium and plasma cells in the lamina propria shows the development of a local immune response (32).

Although the exact mechanism of this process has not been studied yet, intraepithelial lymphocytosis is considered to be the factor responsible for the epithelium damage. The decrease in the number of goblet cells detected in patients not on GFD can be explained by the cytotoxic effect of lymphocytes on epithelial cells. We believe that the decrease in the number of goblet cells may reduce the functionality of the epithelial layer. It is known that goblet cells produce mucus which protects the epithelium from negative impacts. However, according to the recent data obtained in the experiment, it has been found that the goblet cells of the small intestine are involved in the transport of antigens to the dendritic cells and may play an important role in the intestinal immune homeostasis (36).

While most studies of the small intestinal mucosa in coeliac disease focus on the villous height/crypt depth ratio and the number of intraepithelial lymphocytes, our research has shown the importance of analyzing the morphometric parameters of the lamina propria. Our results revealed the differences in the total cell density and cell-specific forms throughout the depth of the lamina propria, as well as its upper and lower parts, depending on the patients' compliance with GFD. In the pathogenesis of coeliac disease, the processes in lamina propria are considered crucial, and they are seen as events preceding the intraepithelial infiltration (13).

According to research literature, the presence of a significant number of inflammatory cells, including polymorphonuclear leukocytes, in the upper part of the lamina propria damages and destroys the villi (37). We have found these changes in children not on GFD.

We have noticed that in the space between the crypts in the lamina propria, the patients not on GFD and those on semistrict GFD had significantly more fibroblasts than those on strict GFD.

Now fibroblasts are believed to play a key role in inflammation and tissue remodeling, and for these reasons they are involved in the pathogenesis of autoimmune diseases such as coeliac disease. Studies on the possibility of fibroblasts playing the role of participants in the pathogenesis of mucosal damage in coeliac disease may reveal new mechanisms of this disease (38). A number of writers report that one of the fibroblast triggers is the activation of the transforming growth factor (TGF-beta 1) (39), while in children with coeliac disease, hyperproduction of TGF-beta 1 in the lamina propria can be found (40). The activation of fibroblasts may lead to changes in extracellular matrix, formation of coarse collagen fibers and reticular fibers and, possibly, under these conditions, it may be accompanied by the de- 
velopment of local fibrosis. This question requires further studies in patients with coeliac disease, especially in those not on GFD in catamnesis.

In the current study of children with coeliac disease, based on a wide range of quantitative parameters of morphometric analysis, we have managed to identify the features of duodenum mucosa structure in reponse to patients' compliance with gluten-free diet (GFD) and thus the purpose of the work has been achieved.

Obviously, this study has its limitations, primarily because this method is invasive. It also requires a well-trained and experienced pathologist to conduct the morphometric analysis of small intestinal mucosa. Despite these limitations, we believe that only quantitative (numerical) data obtained in a morphometric study allow comparing the groups of patients with coeliac disease with differing adherence to GFD and assessing the dynamics of the gradual pathological process in individuals over time, and thus providing a better understanding of the nature of the changes. This is important for the improvement in treatment and prognosis for the disease. Further research in this direction will help to reveal the causes of various outcomes and long-term complications of coeliac disease.

\section{References}

1. McLoughlin R, Sebastian SS, Qasim A et al. Coeliac disease in Europe. Aliment Pharmacol Ther 2003; 18 (s3): 45-48.

2. Catassi C, Cobellis G. Coeliac disease epidemiology is alive and kicking, especially in the developing world. Dig Liver Dis 2007; 39 (10): 908-910.

3. Virta LJ, Kaukinen K, Collin P. Incidence and prevalence of diagnosed coeliac disease in Finland: results of effective case finding in adults. Scand J Gastroenterol 2009; 44 (8): 933-938.

4. Fasano A, Berti I, Gerarduzzi T et al. Prevalence of celiac disease in at-risk and not-at-risk groups in the United States: a large multicenter study. Arch Intern Med 2003; 163 (3): 286-292.

5. Nowier SR, Eldeen NS, Farid MM, Rasol HAA, Mekhemer SM. Prevalence of celiac disease among type 1 diabetic Egyptian patients and the association with autoimmune thyroid disease. Bratisl Lek Listy 2009; 110 (4): $258-262$.

6. Rostom A, Murray JA, Kagnoff MF. American Gastroenterological Association (AGA) Institute technical review on the diagnosis and management of celiac disease. Gastroenterology 2006; 131 (6): 1981-2002.

7. Catassi C, Fasano A. Celiac disease. Curr Opin Gastroenterol 2008; 24 (6): 687-691.

8. Husby S, Koletzko S, Korponay-Szabó IR et al. European Society for Pediatric Gastroenterology, Hepatology, and Nutrition guidelines for the diagnosis of coeliac disease. J Pediatr Gastroenterol Nutr 2012; 54 (1): 136-160.

9. Helms S. Celiac disease and gluten-associated diseases. Altern Med Rev 2005; 10 (3): 172-192.

10. Kagnoff MF. Celiac disease: pathogenesis of a model immunogenetic disease. J Clin Invest 2007; 117 (1): 41-49.

11. Marsh MN. Mucosal pathology in gluten sensitivity. Coeliac Disease. Oxford; Blackwell Scientific Publications, 1992: 136-191.
12. Makovicky P. What can we do to promote the recognition of celiac disease: a report on diagnostic strategies. Bratisl Lek Listy 2010; 111 (3): 163-165.

13. Marsh MN. Gluten, major histocompatibility complex, and the small intestine. A molecular and immunobiologic approach to the spectrum of gluten sensitivity ('celiac sprue'). Gastroenterology 1992; 102 (1): 330-354.

14. Marsh MN, Crowe PT. Morphology of the mucosal lesion in gluten sensitivity. Baillieres Clin Gastroenterol 1995; 9 (2): 273-293.

15. Oberhuber G, Granditsch G, Vogelsang $\mathbf{H}$. The histopathology of coeliac disease: time for a standardized report scheme for pathologists. Eur J Gastroenterol Hepatol 1999; 11 (10): 1185-1194.

16. Corazza GR, Villanacci V. Coeliac disease. J Clin Pathol 2005; 58 (6): 573-574.

17. Corazza GR, Frazzoni M, Dixon MF, Gasbarrini G. Quantitative assessment of the mucosal architecture of jejunal biopsy specimens: a comparison between linear measurement, stereology, and computer aided microscopy. J Clin Pathol 1985; 38 (7): 765-770.

18. Arikan C, Zihni C, Cakir M, Alkanat M, Aydogdu S. Morphometric analysis of small-bowel mucosa in Turkish children with celiac disease and relationship with the clinical presentation and laboratory findings. Dig Dis Sci 2007; 52 (9): 2133-2139.

19. Kupper C. Dietary guidelines and implementation for celiac disease. Gastroenterology 2005; 128 (4 Suppl 1): 121-127.

20. See J, Murray JA. Gluten-free diet: the medical and nutrition management of celiac disease. Nutr Clin Pract 2006; 21 (1): 1-15.

21. Rodrigues AF, Jenkins HR. Investigation and management of coeliac disease. Arch Dis Child 2008; 93 (3): 251-254.

22. Grzenda-Adamek Z, Piatkowska E, Strzepek J, Przybyszewska K, Kruszewska M. Compliance with gluten free diet, physical development and bone mineral status in patients with celiac disease. Prz Lek 2003; 60 (10): 642-644.

23. Hopman EGD, le Cessie S, von Blomberg BME, Mearin ML. Nutritional management of the gluten-free diet in young people with celiac disease in The Netherlands. J Pediatr Gastroenterol Nutr 2006; 43 (1): 102-108.

24. Jadresin O, Misak Z, Sanja K, Sonicki Z, Zizić V. Compliance with gluten-free diet in children with coeliac disease. J Pediatr Gastroenterol Nutr 2008; 47 (3): 344-348.

25. Errichiello S, Esposito O, Di Mase R et al. Celiac disease: predictors of compliance with a gluten-free diet in adolescents and young adults. J Pediatr Gastroenterol Nutr 2010; 50 (1): 54-60.

26. Catassi C, Bearzi I, Holmes GKT. Association of celiac disease and intestinal lymphomas and other cancers. Gastroenterology 2005; 128 (4 Suppl 1): 79-86.

27. Haines ML, Anderson RP, Gibson PR. Systematic review: The evidence base for long-term management of coeliac disease. Aliment Pharmacol Ther 2008; 28 (9): 1042-1066.

28. Cummins AG, Alexander BG, Chung A et al. Morphometric evaluation of duodenal biopsies in celiac disease. Am J Gastroenterol 2011; 106 (1): 145-150.

29. Walker-Smith JA, Guandalini S, Schmitz J, Shmerling DH, Visakorpi JK. Revised criteria for diagnosis of coeliac disease. Report of Working Group of European Society of Paediatric Gastroenterology and Nutrition. Arch Dis Child 1990; 65 (8): 909-911. 
30. Pietzak MM. Follow-up of patients with celiac disease: Achieving compliance with treatment. Gastroenterology 2005; 128 (4): 135-141.

31. Mayer M, Greco L, Troncone R, Auricchio S, Marsh MN. Compliance of adolescents with coeliac disease with a gluten free diet. Gut 1991; 32 (8): 881-885.

32. Marsh MN, Bjarnason I, Shaw J, Ellis A, Baker R, Peters TJ. Studies of intestinal lymphoid tissue. XIV--HLA status, mucosal morphology, permeability and epithelial lymphocyte populations in first degree relatives of patients with coeliac disease. Gut 1990; 31 (1): 32-36.

33. Järvinen TT, Collin P, Rasmussen $M$ et al. Villous tip intraepithelial lymphocytes as markers of early-stage coeliac disease. Scand J Gastroenterol 2004; 39 (5): 428-433.

34. Catassi C, Fabiani E, Iacono G et al. A prospective, double-blind, placebo-controlled trial to establish a safe gluten threshold for patients with celiac disease. Am J Clin Nutr 2007; 85 (1): 160-166.

35. Murray JA. Celiac sprue: to diet or digest. Clin Gastroenterol Hepatol 2005; 3 (7): 629-630.
36. McDole JR, Wheeler LW, McDonald KG et al. Goblet cells deliver luminal antigen to $\mathrm{CD} 103+$ dendritic cells in the small intestine. Nature 2012; 483 (7389): 345-349.

37. Ensari A. Gluten-sensitive enteropathy (celiac disease): controversies in diagnosis and classification. Arch Pathol Lab Med 2010; 134 (6): 826-836.

38. Roncoroni L, Elli L, Doneda $\mathbf{L}$ et al. Isolation and culture of fibroblasts from endoscopic duodenal biopsies of celiac patients. J Transl Med 2009; 7: 40 .

39. Schuppan D. Current concepts of celiac disease pathogenesis. Gastroenterology 2000; 119 (1): 234-242.

40. Hansson T, Ulfgren A-K, Lindroos E, DannAEus A, Dahlbom I, Klareskog L. Transforming growth factor-beta (TGF-beta) and tissue transglutaminase expression in the small intestine in children with coeliac disease. Scand J Immunol 2002; 56 (5): 530-537.

Received July 27, 2012. Accepted October 27, 2013 